Article

\title{
Pregnancy disorders in female workers at the industrial area of Sidoarjo, Indonesia
}

\author{
Firman Suryadi Rahman, ${ }^{1}$ Tri Martiana² \\ ${ }^{1}$ Doctoral Program of Public Health; ${ }^{2}$ Department of Occupational Health and Safety, Faculty of Public Health, \\ Universitas Airlangga, Surabaya, Indonesia
}

\begin{abstract}
Background: The number of female workers in Indonesia has increased and female workers have been discovered to be very vulnerable to several hazards and health problems in the workplace environment linked to their menstrual cycle and pregnancy. Therefore, this study was conducted to analyze risk factors associated with pregnancy disorders in female workers.

Design and Methods: The research was conducted through the use of a cross-sectional design with 307 female workers using simple random sampling. Furthermore, a descriptive analysis was conducted to describe the conditions of the respondents during pregnancy to childbirth process.

Results: The results showed $45 \%$ of respondents had pregnancy disorders, $16 \%$ had miscarriages, and despite the fact most of the prenatal care processes was assisted by doctors or midwives, $2.6 \%$ of the respondents consulted Traditional Birth Attendants, who were also recorded and was found to account for $2.9 \%$ of the deliveries. Moreover, the risk factors associated with pregnancy disorders include vibrations $(\mathrm{P}=0.004)$, irritants $(\mathrm{P}=0.002)$ and repetitive works $(\mathrm{P}=0.009)$.

Conclusions: It is recommended that companies should provide maternal and child health protection and control for any risk associated with female workers.
\end{abstract}

\section{Introduction}

The number of female workers in both the formal and informal work sectors of Indonesia has been discovered to be increasing over the years, with most of them reported to be spending 8 hours per day at work. ${ }^{1}$ This means they are exposed to certain processes within this period which makes the monitoring of their reproductive health very important through the use of indicators such as the Maternal Mortality Rate (MMR) and Infant Mortality Rate (IMR). However, the values for these indicators have been observed to be below the SDGs target in the country. ${ }^{2}$ Therefore, several reproductive health strategies need to be considered in the workplace: these include the prevention and treatment of infertili- ty, maternal and newborn health, family planning, prevention and control of Sexually Transmitted Infections (STIs), and prevention and detection of cancer in the relevant organs. Moreover, some of the possible health problems associated with reproduction among female workers include menstrual cycle disorders, high anemia prevalence, spontaneous abortion, risk of abortion in chemical exposures, and reduced time of breastfeeding and taking care of babies or children. ${ }^{3}$

In Indonesia, the law provides some special protection for female workers such as permission to take leave during their first and second days of menstruation, rest before and after giving birth as well as the restriction from working at night and for over 40 hours a week. ${ }^{4}$ However, the laws are not fully implemented, with some of the women observed to be working more than the set limits as well as the difficulties attached to their rights to obtain maternity leave during the pregnancy. ${ }^{5}$

Female workers possess different abilities and physiology from their male colleagues and have been reported to be very sensitive to some hazards in the workplace environment such as noise, heat, dust, and vibrations. ${ }^{6}$ Moreover, those working for longer periods of time are likely to have higher possibility of exposure $^{7}$ while excessive workload has been found to be affecting their physical and mental health. ${ }^{8}$ This means female workers need to be protected especially during menstrual period, pregnancy, and breastfeeding periods, due to the possibility of several disorders attached to their exposure to hazardous activities during these moments of their lives. ${ }^{9}$ This study was conducted to analyze the situations and factors associated with pregnancy disorders in female workers before, during, and after pregnancy, such as heavy or irregular menstrual bleeding, premenstrual syndrome, dysmenorrheal disorder, and menstrual cycle disorder ${ }^{10}$ as well as abortion or low birth weight infant.

\section{Design and Methods}

A cross-sectional study was conducted on female workers in the Sidoarjo industrial area in East Java Indonesia. It involved the selection of 307 female workers as sample through simple random sampling. The primary data were obtained by using questionnaires

Significance for public health

Female workers possess abilities different from those of their male colleagues and have been reported to be very sensitive to some hazards in the workplace environment such as noise, heat, dust, and vibration. This paper describes the risk factors associated with pregnancy disorders in female workers before, during, and after pregnancy. Such disorders include heavy or irregular menstrual bleeding, premenstrual syndrome, dysmenorrheal disorder, and menstrual cycle disorder. 
designed to determine the conditions of female workers during pregnancy and through the childbirth process in relation to disorders and hazards in the workplace. Moreover, field observation was conducted to cross-check the validity of the information obtained while the data were analyzed using SPSS 23. It is important to note that this research was conducted after ethical approval was obtained from the Faculty of Public Health UniversitasAirlangga Research Ethics Committee.

\section{Results and Discussion}

Table 1 illustrates the socio-demographic characteristic of the respondents $(\mathrm{N}=307)$. A total of 310 questionnaires were distributed in the study area by the field research team and a very high response rate of $99.03 \%$ was recorded: 307 of the respondents answered the questionnaire. The data showed that female workers were present in several industrial locations: $90.2 \%$ of them had the status of permanent employee with binding rights and obligations, $72.3 \%$ was between $36-50$ years, and the highest levels of education were Junior and Senior High School (40.4\% and $43.6 \%$ of the respondents respectively). Furthermore, $53.7 \%$ were recorded to have worked in the company for 11-20 years while $87.3 \%$ work on a shift system of 1-3-2 every week.

As can be seen in Table 2, all of the respondents reported they had been pregnant while working in the company, but the frequency varies with $46.3 \%$ of the respondent having experienced two pregnancies while working. The age at first pregnancy varied: most of the respondent $(73.3 \%)$ had it between $17-25$ years of age while $4.9 \%$ had it at the age of $<17$ years and $1.6 \%$ at $>34$ years. $45 \%$ experienced pregnancy disorders in the form of nausea, vomiting, menstrual issues, and several other problems.

Pregnancy check-ups and antenatal care were routinely conducted: the majority of the visits $(74.6 \%)$ was carried out by midwives, followed by obstetricians with $18.6 \%$, while only $1.3 \%$ consulted Traditional Birth Attendants (TBAs). Moreover, $61.9 \%$ of the child delivery process was assisted by midwives, $35.5 \%$ by doctors, and $2.6 \%$ by TBAs; and the majority (50.5\%) was record-

Table 1. Socio-demographic characteristic of the respondents $(N=307)$.

\begin{tabular}{lcc} 
Variables & N=307 & Percentage (\%) \\
Female worker status & & \\
$\quad$ Permanent & 277 & 90.2 \\
Outsourced & 27 & 8.8 \\
Contingent & 3 & 1.0 \\
Age & & \\
20-35 years old & 59 & 19.2 \\
36-50 years old & 222 & 72.3 \\
51-65 years old & 26 & 8.5 \\
\hline Education level & & \\
Elementary School & 35 & 11.4 \\
Junior High School & 125 & 40.4 \\
Senior High School & 134 & 43.6 \\
University & 13 & 4.2 \\
Duration of work & & \\
$0-10$ & 37 & 12.1 \\
$11-20$ & 165 & 53.7 \\
$21-30$ & 95 & 30.9 \\
$31-40$ & 10 & 3.3 \\
\hline Shift work & & \\
Yes & 268 & 12.7 \\
No & 39 & \\
\hline
\end{tabular}

ed to have happened in the midwife's house, $35.5 \%$ in the hospital, $2.9 \%$ in the respondents' house, and 0.7 at the TBAs. Furthermore, all the babies were found to be generally in good condition with only $5.9 \%$ weighing less than 2500 grams. However, $16 \%$ of the respondents experienced a miscarriage.

Table 3 describes the hazards in the work environment, which include noise, dust, pungent odor, irritant material, vibrations, overload loads, and repetitive works and, according to the simple logistic regression, those affecting pregnancy disorders include vibrations $(\mathrm{P}=0.004)$, irritants $(\mathrm{P}=0.002)$, and repetitive works $(\mathrm{P}$ $=0.009$ ).

This study aimed to describe the influence of the hazards in the work environment on pregnancy disorders. Most of the female workers studied have been working for more than 10 years, meaning they are more likely to be have been exposed to several haz$\operatorname{ards}^{11}$ with the possibilities of several effects on their health. ${ }^{12}$ Moreover, the 1-3-2 work shifts indicate there is an alternation of work duties in the morning, evening, and night each week and this may cause health problems such as sleep and hormonal disorders ${ }^{13}$ and also affect the circadian rhythm inside the women's body, which further leads to irregular menstrual cycles. ${ }^{14}$ This means irregular work and night shifts can cause pregnancy problems. ${ }^{15-17}$

The age of first pregnancy was considered to be generally good but a small percentage was found to have gotten pregnant at a very

Table 2. Pregnancy history of female workers.

Variables Total Percentage (\%)

Pregnancy experiences

$\begin{array}{lcc}1 \text { time } & 90 & 29.3 \\ 2 \text { times } & 142 & 46.3 \\ 3 \text { times } & 57 & 18.6 \\ 4 \text { times } & 13 & 4.2 \\ 5 \text { times } & 5 & 1.6\end{array}$

\begin{tabular}{lcc} 
Age of first pregnancy & & \\
$<17$ years & 15 & 4.9 \\
$17-25$ years & 225 & 73.3 \\
$26-34$ years & 62 & 20.2 \\
$>34$ years & 5 & 1.6 \\
\hline
\end{tabular}

Pregnancy disorders

$\begin{array}{lll}\text { Yes } & 138 & 45 \\ \text { No } & 169 & 55\end{array}$

$\begin{array}{lcc}\text { Pregnancy check-ups } & & \\ \text { Specialist } & 57 & 18.6 \\ \text { Doctor } & 8 & 2.6 \\ \text { Midwife } & 229 & 74.6 \\ \text { Public Health Center } & 9 & 2.9 \\ \text { Traditional Birth Attendant } & 4 & 1.3\end{array}$

Person assisting the delivery process

$\begin{array}{lrr}\text { Doctor } & 109 & 35.5 \\ \text { Midwife } & 190 & 61.9\end{array}$

$\begin{array}{lll}\text { Traditional Birth Attendant } & 8 & 2.6\end{array}$

\begin{tabular}{lcc} 
Place of delivery & & \\
Hospital & 109 & 35.5 \\
Maternity hospital & 32 & 10.4 \\
Midwife's house & 155 & 50.5 \\
Patient's house & 9 & 2.9 \\
$\quad$ Traditional Birth Attendant House & 2 & 0.7 \\
\hline $\begin{array}{l}\text { Miscarriage/abortus experiences } \\
\text { Yes }\end{array}$ & 49 & \\
No & 258 & 84 \\
Weight of baby & & \\
$\quad<2,500$ grams & 18 & 5.9 \\
2,500 grams & 289 & 94.1 \\
\hline
\end{tabular}


young age when the reproductive organs are not anatomically and physiologically ready to function properly, thereby causing several disorders such as miscarriages, babies born with weight less than 2500 grams, and others. ${ }^{18,19}$

The Indonesian government has implemented different policies to improve maternal and child health and protect menstruating, pregnant, and postpartum workers, but these efforts do not consider the fact that the current Maternal Mortality Rate has not yet reached the SDGs target. ${ }^{20}$ This has been reported to be caused by inappropriate antenatal care and examination by Traditional Birth Attendant (TBA). ${ }^{21}$ However, several efforts have been made by the government to collaborate with midwives and traditional birth attendants to reduce the incidence of maternal mortality ${ }^{22}$ but difficulties have been observed in implementing these strategies in remote areas. Furthermore, pregnancy check and childbirth processes are usually conducted in hospitals or midwives houses through the assistance of trained medical personnel, but few people were reported to be still making use of the TBA and this was found to be causing several problems such as miscarriage, bleeding after birth, maternal death, and unhealthy babies. ${ }^{23}$ Therefore, there is a need to improve the knowledge of TBAs through training in order to provide adequate assistance to midwives during the birth process. $^{24}$

\section{Some of the working conditions observed to be causing pregnancy disorder include:}

\section{WBV (Whole Body Vibration)}

Whole-Body or Hand-Arm vibration in the workplace has detrimental effects on the health of workers through its effects on several organs and systems such as the reproductive organs, ${ }^{25}$ causing health problems and pregnancy disorders. It has been reported to cause abnormal uterus positioning, abnormal menstruation, and abortion ${ }^{26}$ and in extreme cases, menstrual disorder, anomalies in foetal position, and stillbirths. ${ }^{27}$ Therefore, there is a need for protection and administrative efforts to reduce the impact of WBV on workers, especially the female ones who are very vulnerable to such hazards in the work environment. ${ }^{28}$

\section{Irritant}

An irritant is a chemical causing damages to the body directly through inhalation, skin contact, and the digestive tract. It can affect the hormones, which further causes pregnancy disorders in female workers. ${ }^{29}$

\section{Repetitive work}

These are works often repeated in the workplace and with the ability to cause psychological and health problems. According to OSHA, any activity conducted repeatedly in less than 30 seconds is categorized as repetitive motion, and any work done permanently and repetitively for 6 hours has effects. ${ }^{30}$ Therefore, repetitive work and motion have the ability to increase risks of miscarriage, preterm labor and birth, low birth weight, preeclampsia ${ }^{31}$ and directly affect the development of the fetus in the body. Moreover, in a continuous condition, it causes abortion and premature babies $^{32}$ and if conducted in a standing position, it is more dangerous due to its ability to cause restriction or symptoms of preterm labor. ${ }^{33}$ Therefore, the company is required to pay more attention to the health of female workers in order to avoid several health problems during pregnancy. ${ }^{34}$

\section{Conclusions}

Female workers in industrial environments are prone to experience pregnancy disorders. This is associated with the pregnancy check-ups and deliveries conducted by TBAs and the exposure to several hazards in the work environment such as vibrations, irritants, and repetitive works. Therefore, companies are required to focus on reducing the hazards in the work environment to protect female workers from pregnancy disorders.

Table 3. Hazard in the work environment.

\begin{tabular}{|c|c|c|c|}
\hline Hazard & Respondents with pregnancy disorders & Respondents without pregnancy disorders & P-Value \\
\hline $\begin{array}{l}\text { Noise } \\
\text { Yes } \\
\text { No }\end{array}$ & $\begin{array}{c}103(74.6 \%) \\
35(25.4 \%)\end{array}$ & $\begin{array}{l}127(75.1 \%) \\
42(24.9 \%)\end{array}$ & 0.571 \\
\hline $\begin{array}{l}\text { Dust } \\
\text { Yes } \\
\text { No }\end{array}$ & $\begin{array}{l}98(71 \%) \\
40(29 \%)\end{array}$ & $\begin{array}{c}116(68.6 \%) \\
53(31.4 \%)\end{array}$ & 0.605 \\
\hline $\begin{array}{l}\text { Odor } \\
\text { Yes } \\
\text { No }\end{array}$ & $\begin{array}{l}49(35.5 \%) \\
89(64.5 \%)\end{array}$ & $\begin{array}{c}49(29 \%) \\
120(71 \%)\end{array}$ & 0.076 \\
\hline $\begin{array}{c}\text { Irritant } \\
\text { Yes } \\
\text { No }\end{array}$ & $\begin{array}{l}42(30.4 \%) \\
96(69.9 \%)\end{array}$ & $\begin{array}{l}70(41.4 \%) \\
99(58.6 \%)\end{array}$ & 0.002 \\
\hline $\begin{array}{c}\text { Vibration } \\
\text { Yes } \\
\text { No }\end{array}$ & $\begin{array}{l}75(54.3 \%) \\
63(45.7 \%)\end{array}$ & $\begin{array}{l}78(46.2 \%) \\
91(53.8 \%)\end{array}$ & 0.004 \\
\hline $\begin{array}{l}\text { Overload load } \\
\text { Yes } \\
\text { No }\end{array}$ & $\begin{array}{c}17(12.3 \%) \\
121(87.7 \%)\end{array}$ & $\begin{array}{c}29(17.2 \%) \\
140(82.8 \%)\end{array}$ & 0.650 \\
\hline $\begin{array}{l}\text { Repetitive work } \\
\text { Yes } \\
\text { No }\end{array}$ & $\begin{array}{l}72(52.2 \%) \\
66(47.8 \%)\end{array}$ & $\begin{array}{c}106(62.7 \%) \\
63(37.3)\end{array}$ & 0.009 \\
\hline
\end{tabular}


Correspondence: Tri Martiana, Department of Occupational Health and Safety, Faculty of Public Health, Universitas Airlangga, Surabaya 60115, East Java, Indonesia.

Tel.: +62315920948 - Fax: +62315924618

E-mail: tri.martiana@fkm.unair.ac.id

Key words: Female workers; pregnancy disorders; maternal and child health; hazard.

Contributions: All authors contributed equally. Prof Tri Martiana has been a supportive and caring supervisor in this study.

Conflict of interest: The authors declare no potential conflict of interest.

Funding: This study was supported by Universitas Airlangga.

Acknowledgments: We would like to thanks to civitas academica Universitas Airlangga.

Clinical trials: This study did not involve any clinical trials.

Conference presentation: Part of this paper was presented at the $4^{\text {th }}$ ISOPH 2019, 2019 October 29-31, Griffith University, Australia.

Received for publication: 6 March 2020.

Accepted for publication: 13 June 2020.

OCopyright: the Author(s), 2020

Licensee PAGEPress, Italy

Journal of Public Health Research 2020:9:1824

doi:10.4081/jphr.2020.1824

This work is licensed under a Creative Commons Attribution NonCommercial 4.0 License (CC BY-NC 4.0).

\section{References}

1. World Bank. Labor Force data. ILO Data Sheet for Indonesia 2017. Available from: https://www.ilo.org/wcmsp5/groups/public/---asia/---robangkok/---ilo-jakarta/documents/publication/ wcms_613626.pdf. Accessed on: 18 January 2020.

2. Martiana T, Rochmah TN, Alayyannur PA, et al. Characteristics of the Maternal and Child Health Service of Female Workers with Maternal and Child Health Status in Indonesia. Indian J Publ Health Res Dev 2019;10:1499-503.

3. Banerjee B. Physical Hazards in Employment and Pregnancy Outcome. Indian J Commun Med 2009;34:3-8.

4. Republic of Indonesia. Regulation No 13/2013 about labor law 2013. Available from: https://www.ilo.org/dyn/natlex/ docs/SERIAL/64764/56412/F811830039/IDN64764\%20New. pdf. Accessd on: 18 January 2020.

5. Bonzini M, Coggon D, Godfrey K, et al. Occupational physical activities, working hours and outcome of pregnancy: findings from the Southampton Women's Survey. Occup Environ Med 2009;66:685-90.

6. Johnson CY, Rocheleau CM, Lawson CC, et al. Factors affecting workforce participation and healthy worker biases in U.S. women and men. Ann 2017;27:558-562.e2

7. Rahman FS, Martiana T. Analysis of factors related to maternal health in female workers in the industrial area of Sidoarjo, Indonesia. J Public Health Africa 2019;10.

8. Martiana T, Rahman FS, Mahdang P, et al. The Influence of Work Factors on Reproductive Health of Female Workers in
Sidoarjo Industrial Area, Indonesia.

9. Gesser-Edelsburg A, Shir-Raz Y, Hayek S, et al. Despite awareness of recommendations, why do health care workers not immunize pregnant women? Am J Infect Control 2017;45:436-9.

10. Taek-Rim K. Reproductive Toxic Chemicals at Work and Efforts to Protect WorkersHealth: A Literature Review. Safety Health Work 2017;8:143-50.

11. Paul M. Occupational reproductive hazards. The Lancet 1997;349:1385-8.

12. Yoon JH, Hong JS, Roh J,et al. Dose-response relationship between noise exposure and the risk of occupational injury. Noise Health 2015;17:43.

13. Wright KP, Bogan RK, Wyatt JK. Shift work and the assessment and management of shift work disorder (SWD). Sleep Med Rev 2013;17:41-54.

14. Zhu JL, Hjollund NH, Olsen J. Shift work, duration of pregnancy, and birth weight: The National Birth Cohort in Denmark. Am J Obstet Gynecol 2004;191:285-91.

15. Dumont M, Paquet J. Progressive decrease of melatonin production over consecutive days of simulated night work. Chronobiol Int 2014 1;31:1231-8.

16. Lunn RM, Blask DE, et al. Health consequences of electric lighting practices in the modern world: A report on the National Toxicology Program's workshop on shift work at night, artificial light at night, and circadian disruption. Sci Total Environ 2017;607-608:1073-84.

17. Straif K, Baan R, Grosse Y, Secretan B, et al. Carcinogenicity of shift-work, painting, and fire-fighting. Lancet Oncol 2007;8:1065-6.

18. WHO. Maternal Mortality.Geneva.2010.

19. Gaudie J, Mitrou F, Lawrence D,et al. Antecedents of teenage pregnancy from a 14-year follow-up study using data linkage. BMC Public Health 2010;10:63.

20. Cleland JG, Ndugwa RP, Zulu EM. Family planning in subSaharan Africa: progress or stagnation? Bull W H O 2011;89:137-43.

21. Ohaja M, Murphy-Lawless J. Unilateral collaboration: The practices and understandings of traditional birth attendants in southeastern Nigeria. Women Birth 2017;30:e165-71.

22. Keri L, Kaye D, Sibylle K. Referral practices and perceived barriers to timely obstetric care among Ugandan traditional birth attendants (TBA). Afr Health Sci 2010;10:75.

23. Kaingu CK, Oduma JA, Kanui TI. Practices of traditional birth attendants in Machakos District, Kenya. J of Ethnopharmacol 2011;137:495-502.

24. Sibley LM, Sipe TA, Barry D. Traditional birth attendant training for improving health behaviours and pregnancy outcomes. Cochrane Datab System Rev 2012(8).

25. Mansfield NJ. Human response to vibration. Florida: CRC press; 2004.

26. Seidel H. Selected Health Risks Caused by Long-Term, Whole-Body Vibration. J Publ Health 1993;23:589-604.

27. Anand N, Gandhi A, Verma V, et al. Design and Development of Ergonomic Workstation for Pregnant Workers in Readymade Garment Industry. In: Capaldi N., Idowu S., Schmidpeter R. (eds) Dimensional Corporate Governance. Switzerland: Springer International Publishing; 2017.

28. Johanning E. Whole-body vibration-related health disorders in occupational medicine-an international comparison. Ergonomics 2015;58:1239-52.

29. Wang BJ, Wu JD, Sheu SC, et al. Occupational hand dermatitis among cement workers in Taiwan. J Formos Med Ass 2011;110:775-9. 
30. Jurewicz J, Radwan M, Sobala W, et al. Effects of occupational exposure-is there a link between exposure based on an occupational questionnaire and semen quality? Syst Biol Reprod Med 2014;60:227-33.

31. Katz VL. Work and work-related stress in pregnancy. Clin Obstet Gynecol 2012;55:765-73.

32. Ministry of Health RI. Health reproduction for female worker.
Jakarta: MoH Press; 2009.

33. Boivin DB, Boudreau P. Impacts of shift work on sleep and circadian rhythms. Pathol Biol 2014;62:292-301.

34. Figueiro MG, Steverson B, Heerwagen J, et al. The impact of daytime light exposures on sleep and mood in office workers. Sleep Heal 2017;3:204-15. 